\title{
Consequências da Aquisição Tardia da Língua Brasileira de Sinais na Compreensão Leitora da Língua Portuguesa, como Segunda Língua, EM Sujeitos Surdos ${ }^{1}$
}

\author{
Consequences of Late ACQUiSITION of BRAZILIAN Sign LANGUAGE ON READING \\ Comprehension of the Portuguese Language as a Second Language for \\ DeAF PEOPLE
}

\begin{abstract}
RESUMO: este artigo investigou sobre as consequências da aquisição da língua de sinais tardiamente na compreensão leitora em língua portuguesa como segunda língua por parte de surdos sinalizantes da língua brasileira de sinais. Para visualizar tais consequências, aplicou-se um teste de compreensão de língua de sinais, retirado do material Instrumento de Avaliação da Língua de Sinais (IALS), e um teste de compreensão leitora de língua portuguesa adaptado do Programa Internacional de Avaliação de Estudantes (PISA). Participaram deste estudo cinco surdos de nascença do sexo masculino, com idades de 19 a 41 anos e com diferentes idades de aquisição da língua de sinais. Os resultados apontaram como principal consequência a falta de estratégias para identificar a ideia principal do texto. Demonstraram também que apesar do fator idade de aquisição da língua de sinais interferir bastante na compreensão leitora da língua portuguesa, há outros fatores a considerar como: o contato com outros surdos que sejam fluentes, o apoio e motivação por parte da família no uso das duas línguas (Libras e Língua Portuguesa), a presença da língua de sinais durante a trajetória escolar, bem como metodologias de ensino de língua portuguesa que auxiliem os surdos a descobrir suas próprias estratégias de construção de sentido e ainda os fazerem detectar as diferenças de modalidade das línguas produzidas, bem como as particularidades de cada língua envolvida e ainda, o que é comum a ambas as línguas.
\end{abstract}

PALAVRAS-CHAVE: Educação Especial. Língua Brasileira de Sinais. Aquisição da Linguagem. Leitura Compreensiva.

\begin{abstract}
This paper investigated the consequences of late acquisition of sign language on reading comprehension of the Portuguese language as a second language by deaf who sign in Brazilian Sign Language. In order to look at the consequences, we applied a sign language comprehension test, taken from the Assessment Instrument materials of sign language (IALS), and Portuguese reading comprehension test adapted from the Portuguese Program for International Student Assessment (PISA). The participants were five people who were deaf from birth, males aged 19-41 years, who had acquired sign language at different ages. The results showed that the main consequence was a lack of strategies for identifying the main idea of the text. The results also showed that despite the factor of age of acquisition of sign language greatly interfering reading comprehension of Portuguese, there are other factors to consider, such as: contact with other deaf people who are fluent, support and motivation from family in the use of the two languages (Libras and Portuguese), the presence of sign language during school life. Another consideration are methodologies for teaching the Portuguese language in order to assist deaf people in discovering their own strategies for constructing meaning as well as showing them how to detect differences that occur in different language modes, and the singularities of each language involved and what is common to both languages.
\end{abstract}

KEYWORDS: Special Education. Brazilian Sign Language. Language Acquisition. Reading Comprehension.

\footnotetext{
${ }^{1}$ http://dx.doi.org/10.1590/S1413-65382115000200008

${ }^{2}$ Doutoranda do Programa de Pós-Graduação em Linguística da Universidade Federal de Santa Catarina. Docente do departamento de Língua Brasileira de Sinais do Instituto Federal de Educação, Ciência e Tecnologia de Santa Catarina, Palhoça, SC, Brasil. slima@ifsc.edu.br; simonesgls@gmail.com
} 


\section{Introduçấo}

Este artigo apresenta uma discussão sobre a aquisição tardia da língua de sinais e sua influência na compreensão leitora de uma segunda língua, de natureza oral, nos sujeitos surdos.

De início, tomou-se como base a perspectiva chomskyana da linguagem e a Hipótese do Período Crítico para a aquisição da linguagem. Segundo a teoria gerativa de Chomsky, a faculdade da linguagem é parte da mente humana que precisa ser despertada para se desenvolver a partir da experiência vivida com a comunidade à qual o sujeito pertence. Supóe também que o indivíduo estaria mais predisposto a desenvolver suas capacidades em um determinado período de sua vida. No entanto, caso o ele não acesse o dispositivo da faculdade da linguagem por falta de acesso a uma língua ou por isolamento linguístico e social, após o período crítico/sensível de aquisição, ainda poderia acessar tal dispositivo, porém com consequências que variam de acordo com a idade e também com o meio social e os tipos de input recebidos (QUADROS, 2008).

A hipótese do período crítico geralmente se refere ao desenvolvimento neurológico, ou seja, às etapas de maturação cerebral que ocorrem desde o nascimento e ao input para adquirir a língua. Tal hipótese postula que as mudanças ocorrem no cérebro até o final do período da puberdade e que a idade ideal para a aquisição de uma língua é nos dez primeiros anos de vida de uma criança. Esse período se refere ao espaço de tempo durante o qual a interação com o meio e seus pares linguísticos é necessária para estimular a característica inata que os humanos têm para linguagem (FERRARI, 2007).

Lenneberg (1967) foi o principal defensor da existência desse período crítico para aquisição de línguas. De acordo com sua teoria, após o período crítico, a capacidade de aquisição e aprendizagem de línguas começa a diminuir por volta dos 12 anos. Depois dessa idade, a fluência só viria com muito esforço. Os fatos que podem comprovar a existência de um período crítico para a aquisição da linguagem é a falta de inputs linguísticos como os casos de Isabele, Genie e Chelsea ${ }^{3}$, que foram isoladas linguística e socialmente e também os casos de surdez congênita Isso se explica devido aos pais serem ouvintes (sem conhecimento da língua de sinais) e não exporem seus filhos surdos a língua de sinais, naturalmente, nos primeiros anos de vida.

No entanto, no âmbito dos Estudos Surdos ainda são poucas as pesquisas que investigam o atraso de aquisição de uma primeira língua e sua influência na aprendizagem de outras. Ramírez, Lieberman e Mayberry (2012) cita, o estudo de Mayberry e Eichen (1991) que usaram uma tarefa de recordar sentenças com quarenta e nove sinalizantes surdos, os quais começaram a aquisição da American Sign Language (ASL) - em português, Língua de Sinais Americana - em uma variedade de idades. Os resultados desse estudo apontam que a idade de início de aquisição teve efeitos significativos sobre o desempenho em todos os níveis da estrutura linguística.

Mayberry e Lock (2003), a partir de um estudo com 54 participantes de diferentes fundos de linguagem, verificaram que a aprendizagem de uma segunda língua (L2) em idade mais avançada pode resultar em semelhante proficiência nativa, mas a aquisição de uma primei-

\footnotetext{
${ }^{3}$ Isabele ficou escondida em um sótão e, aparentemente, nunca havia falado com ninguém, recebendo atenção mínima para sobrevivência física. Ela foi descoberta quando tinha seis anos de idade e seu desenvolvimento cognitivo era de uma criança de dois anos. Genie, uma menina que passou isolada desde um ano e seis meses aos 13 anos e sete meses de idade, sofria maus tratos e vivia isolada em um quarto e amarrada a uma cadeira. Chelsea foi considerada retardada mental nos seus primeiros anos de infância, porém aos 31 anos descobriram que na verdade era surda (FERRARI, 2007).
} 
ra língua (L1) em uma idade mais avançada mostra que a proficiência diminui e há déficits linguísticos em todas as línguas posteriormente adquiridas, independentemente da modalidade.

No Brasil, mais de $90 \%$ das crianças surdas nascem de pais ouvintes que não usam a língua de sinais (STROBEL, 2008; FERNANDES; MOREIRA, 2009). Como resultado, as crianças surdas são frequentemente expostas à língua de sinais como primeira língua em um intervalo de idade bem além da infância (QUADROS; CRUZ, 2011). Os estudos de aquisição da linguagem, em crianças surdas, revelam que o seu desenvolvimento segue as mesmas etapas das crianças ouvintes, pois segue princípios universais como a existência de um viés substantivo e a relação entre o tamanho do vocabulário e da complexidade gramatical. Além disso, esses princípios mostram que são independentes da modalidade por meio da qual a língua é transmitida, se é em sinais ou de forma oral.

Vale destacar aqui que assim como outras línguas de sinais, a Libras é linguisticamente equivalente a línguas faladas e obedece a regras linguísticas ao nível da fonologia, morfologia, sintaxe e semântica (QUADROS; KARNOPP, 2004).

Vários autores (QUADROS, 1997; RUIZ; ORTEGA, 1993; PETITTO; MARANETTE, 1991) que realizaram estudos com filhos surdos de pais surdos proficientes comprovam essa tese do desenvolvimento da aquisição da linguagem, porém o que diferencia os filhos surdos de pais ouvintes é o input não acessível. Em outras palavras, o que interrompe ou atrasa a aquisição da linguagem na criança surda é a falta de interação por meio de uma língua acessível aos seus sentidos, ou seja, a língua de sinais.

Mesmo que a criança surda receba próteses auditivas ou implantes cocleares e participe de um programa intensivo de reabilitação auditiva, a língua oral terá de ser ensinada sistematicamente, ensino que requer tempo que equivale há anos. Sem a língua de sinais, esses anos passam sem a criança internalizar os conceitos das coisas e acontecimentos à sua volta, apenas fazendo o esforço para repetir sons, o que levará a um atraso visível na linguagem percebido até mesmo por leigos.

Quadros e Cruz (2011, p.34) afirmam que “[...] a aquisição da primeira língua de forma consistente em um período considerado normal oferece uma base linguística consolidada para a aquisição de uma segunda língua, assim como observado em outros contextos bilíngues". Destaca-se aqui que existem evidências de que a situação majoritária ou minoritária da primeira língua da criança, a valorização dessa língua na comunidade e sua utilização como instrumento para tarefas de alfabetização afetam os resultados linguísticos e cognitivos da criança. Nesse sentido, a experiência e o contexto linguístico da criança surda se associam diretamente ao fator idade de aquisição.

Outro ponto importante para este estudo é a questão da compreensão da leitura da língua portuguesa como segunda língua (L2) feita por surdos sinalizantes4. O processo de leitura envolve compreender um texto escrito através das habilidades fonêmicas, decodificação dos vocábulos e apreensão do significado e mensagens do texto, implicando uma maturidade

${ }^{4}$ Usa-se o termo surdo sinalizante por haver outros surdos que optam pelo termo oralizar - surdos oralizados - são comumente pessoas com grau leve de surdez e fazem uso de suporte como próteses auditivas e ou implantes cocleares, no entanto há também os surdos sinalizadores e que oralizam de acordo com a situação linguística no momento da interação. Este estudo foca na comunidade de sinalizantes da língua de sinais e que utilizam a modalidade escrita da língua portuguesa. 
que depende das experiências e oportunidades de desenvolvimento da linguagem. $\mathrm{O}$ aspecto mais básico da leitura relaciona-se com a compreensão, posto que sem compreensão não se pode efetivamente dizer que a leitura ocorreu.

Acontece, no entanto, que por se tratar de uma língua de natureza oral-auditiva, generaliza-se a ideia do senso comum de que para ler é necessário ouvir e assim a educação de surdos, principalmente a alfabetização, passou a ter como objetivo fazer o surdo falar e ouvir para que pudesse ser alfabetizado. Martins (2005) pesquisou sobre a formação de leitores surdos e destacou que antes da década de 70 ,

[...] educadores amparados no modelo de processamento ascendente (buttonup) concebiam a leitura como uma habilidade a ser dominada pelas crianças surdas, decorrentes de um aprendizado particular, tendo como base o conhecimento prévio da língua (oral). A partir da aplicação de regras das correspondências entre fonemas e grafemas, enfatizavam o trabalho com reconhecimento de letras, sílabas e palavras, até chegar ao nível de decifração das frases (MARTINS, 2005, p.42).

No presente estudo, entende-se que a compreensão da leitura da língua portuguesa ocorre quando o leitor surdo, diferente de ler letra por letra, passa a usar seu conhecimento prévio e seus recursos cognitivos para estabelecer antecipaçóes sobre o conteúdo do texto, fixando-se neste para verificá-las. Dito de outro modo, o processo de leitura ocorre quando o surdo é capaz de lançar hipóteses e processar os elementos que compóem o texto. E, para tanto, é imprescindível uma base linguística consistente de L1.

Assume-se aqui o ato de ler a partir de uma concepção interacional da língua, onde o sentido de um texto é construído na interação entre texto e sujeito. Nessa concepção, Koch e Elias (2006, p.11) definem a leitura como:

[...] uma atividade interativa altamente complexa de produção de sentidos, que se realiza evidentemente com base nos elementos linguísticos presentes na superfície textual e na sua forma de organizaçáo, mas requer a mobilização de um vasto conjunto de saberes no interior do evento comunicativo.

Nesse sentido, o estudo das consequências do atraso na aquisição de primeira língua (língua de sinais) e sua influência na compreensão leitora de uma segunda língua (língua portuguesa), por surdos, pode contribuir na construção de políticas linguísticas e educacionais significativas para o desenvolvimento humano e social das pessoas surdas e também nas discussóes acerca da existência de um período mais sensível ao aprendizado de línguas.

\section{Método}

Para realizar o estudo sobre as consequências da aquisição tardia de L1 na compreensão leitora em segunda língua de sujeitos surdos, optou-se por realizar um Estudo de Caso, o qual é para Lüdke e André (1986 apud VENTURA, 2007, p.384), “[...] o estudo de um caso simples e específico ou complexo e abstrato e deve ser sempre bem delimitado. Pode ser semelhante a outros, mas é também distinto, pois tem um interesse próprio, único, particular e representa um potencial na educação". Em outras palavras, o estudo de caso tem como objetivo 
investigar um caso específico, bem delimitado, contextualizado em tempo e lugar, para que se possa realizar uma busca circunstanciada de informaçóes.

O presente artigo traz um estudo de caso múltiplo, pois envolve mais de um indivíduo. Ou seja, cinco surdos ${ }^{5}$ de diferentes idades de aquisição de L1, conforme Quadro 1:

\begin{tabular}{|l|c|c|}
\hline Surdos & Idade de Aquisiçáo de L1 & Idade Atual \\
\hline Léo & 1 ano & 23 anos \\
\hline Cris & 4 anos & 19 anos \\
\hline Beto & 8 anos & 32 anos \\
\hline Pedro & 15 anos & 41 anos \\
\hline Felipe & 25 anos & 26 anos \\
\hline
\end{tabular}

Quadro 1: idade de aquisição de L1.

Fonte: elaboração própria.

Para seleção dos participantes do estudo, além do fator de diferentes idades de aquisição da língua brasileira de sinais, levou-se em consideração fatores como: ser surdo de nascença com grau de surdez profundo, filhos de pais ouvintes e idades que variem entre 19 a 45 anos, pois são fatores mais próximos possíveis da realidade brasileira.

Para medir tais consequências, utilizou-se um teste de compreensão da Libras por meio do Instrumento de Avaliação de Língua de Sinais (IALS), de Quadros e Cruz (2011) e um teste de compreensão de leitura da língua portuguesa e adaptado de uma questão do Programa Internacional de Avaliação de Estudantes (PISA).

\subsection{Teste de Linguagem Compreensiva do IALS}

O teste de linguagem compreensiva do IALS foi aplicado com o objetivo de verificar o nível de compreensão da língua de sinais e sua relação com as diferentes idades de aquisição e seus históricos linguísticos. O IALS foi elaborado para avaliar o desenvolvimento da linguagem em pessoas surdas (crianças a partir dos quatro anos, adolescentes e adultos) fluentes da língua de sinais, "visando verificar o nível de desenvolvimento linguístico, acompanhar o processo de aquisição da linguagem e estabelecer medidas de intervenção ou estimulação linguística, se necessário" (QUADROS; CRUZ, 2011, p.45).

O teste de linguagem compreensiva do IALS é um teste por meio do qual se avalia o processamento das informaçóes sinalizadas. Destaca-se aqui que é um teste em que não é necessário utilizar a língua de sinais, o que possibilita que os participantes, com alteraçóes na linguagem expressiva, demonstrem o que realmente compreendem. Nesse teste o participante seleciona e organiza figuras que correspondem às sentenças e às histórias sinalizadas por um professor surdo. O material utilizado na avaliação é disponibilizado pelo IALS e corresponde a um DVD com figuras coloridas, ficha de respostas, sentenças e histórias sinalizadas.

As tarefas do teste são distribuídas em três fases, com níveis crescentes de complexidade sintática discursiva e duas etapas de aplicação para as três fases, sendo que a primeira

\footnotetext{
${ }^{5}$ Os nomes usados são fictícios a fim de preservar a identidade dos participantes. Todos participantes assinaram um termo de livre esclarecido antes de participarem do estudo.
} 
etapa corresponde à aplicação de tarefas de demonstração e a segunda de avaliação. No presente estudo ignorou-se a etapa de demonstração por se tratar de adultos surdos e as instruçôes de como realizar o teste foram dadas pela pesquisadora, em língua de sinais, em conformidade com as instruções do IALS.

A aplicação do teste inicia com a proposição de cinco tarefas para fase I e II. As tarefas são realizadas do seguinte modo: o participante assiste a uma sentença sinalizada (que consta no DVD), em seguida recebe três figuras e seleciona a que corresponde à sentença sinalizada. A fase III apresenta uma tarefa diferente que consiste em assistir uma história sinalizada (que consta no DVD) e em seguida o participante recebe oito figuras, seleciona as que correspondem à história assistida e as organiza conforme a sequência da história. $\mathrm{O}$ desempenho do participante é registrado na ficha de avaliação (que consta no DVD).

Para computar os resultados, Quadros e Cruz (2011) explicam que nas tarefas de avaliação das Fases I e II, cada figura selecionada corretamente recebe um valor de $20 \%$. Logo, se o participante acertar a seleção de cinco tarefas, completará $100 \%$ e receberá o conceito de "excelente"; $80 \%$ de acerto, o conceito é "bom" e de 60\% a 0\%, o conceito é "insuficiente". Os resultados da Fase III são computados em duas etapas: primeira (Fase III A) verifica-se se o participante seleciona as figuras corretamente, descartando o que não faz parte da história. Segunda (Fase III B), verifica-se se o participante organiza as figuras na sequência da história. As porcentagens das duas etapas, respectivamente, ficam distribuídas da seguinte maneira:

\section{[...] Se o participante:}

Selecionar as cinco figuras pertencentes à história e eliminar as três não pertencentes, atingirá o percentual de $100 \%$ de acerto. O conceito "excelente" é atribuído.

Selecionar corretamente alguma figura pertencente a história e eliminar alguma não pertencente, atingirá 50\% de acerto. O conceito "bom" é atribuído.

Selecionar as oito figuras, atingirá $0 \%$ de acerto. O conceito "insuficiente" é atribuído.

[...] Se o participante:

Organizar as cinco figuras da história, atingirá o percentual de 100\%. O conceito "excelente" é atribuído.

Organizar parcialmente as cinco figuras da história, atingirá o percentual de $50 \%$. O conceito "bom" é atribuído.

Organizar incorretamente as cinco figuras, atingirá o percentual de $0 \%$. O conceito "insuficiente" é atribuído (QUADROS; CRUZ, 2011, p.55).

Em seguida aplicou-se um teste de compreensão leitora composto por um texto do Programa Internacional de Avaliação de Estudantes (PISA).

\subsection{Teste de COMPREENSÃo de LEITURA}

O PISA é uma iniciativa internacional de avaliação comparada, sendo aplicado a estudantes na faixa dos 15 anos, idade em que se pressupóe o término da escolaridade básica obrigatória na maioria dos países. O objetivo do PISA é produzir indicadores que contribuam para a discussão da qualidade da educação nos países participantes, de modo a subsidiar políti- 
cas de melhoria do ensino básico. A avaliação ${ }^{6}$ procura verificar até que ponto as escolas de cada país participante estão preparando seus jovens para exercer o papel de cidadãos na sociedade contemporânea.

A avaliação do PISA sobre a Leitura é constituída por um conjunto de questóes composto por cadernos, com textos de vários gêneros textuais, seguidos por questóes de múltipla escolha e outras dissertativas curtas ( o estudante responde uma única palavra, frase curta, fórmula ou número) e longas (o estudante deve construir uma resposta mais explicativa).

Optou-se por utilizar como base um dos textos do PISA, adaptando-o à particularidade dos sujeitos surdos utentes da língua de sinais pelo fato de ainda não haver um teste de compreensão de leitura da língua portuguesa como segunda língua, que envolva o texto como um todo, específico para estudantes Surdos sinalizadores da Libras.

E ainda por compartilhar a perspectiva de Leitura adotada pelo PISA, a qual é vista “[...] como um processo 'ativo', que implica náo apenas a capacidade para compreender um texto, mas a capacidade de refletir sobre ele e de envolver-se com o texto, a partir das ideias e experiências próprias" (INEP, 2010).

O texto selecionado para o teste de compreensão leitora do presente artigo bem como suas questões de interpretação estão disponíveis no site do Inep, localizado no guia denominado de Itens, onde constam os itens liberados de leitura, ou seja, vários textos já aplicados com suas correçóes e pontuações.

A seleção do texto foi pensada de acordo com um gênero textual usual pelos surdos, assim se escolheu um texto curto, para que motivasse os participantes, do gênero aviso - Texto R401_Supermercado. As questóes do texto foram traduzidas para Libras as quais envolveram duas questóes de múltipla escolha, uma questão dissertativa curta e duas questóes dissertativas longas, sendo uma com necessidade de reflexão e outra explicativa. As respostas dos participantes foram registradas pelos mesmos, na escrita da língua portuguesa. Ao final do teste, solicitou-se um resumo do texto lido, em Libras, registrado por meio de filmadora.

Cada questão possui um objetivo ${ }^{7}$ :

- Questáo 2: Integrar e interpretar: Entender o sentido geral de um texto. Identificar a ideia principal de um texto curto associando duas informaçôes adjacentes.

- Questão 3: Acessar a informação e localizá-la: Localizar a informaçáo. Localizar uma correspondência sinônima em um texto curto.

- Questão 4: Integrar e interpretar: Entender o sentido geral de um texto. Identificar o objetivo de uma parte de um texto informativo curto.

- Questão 5: Refletir e avaliar: Refletir sobre o conteúdo de um texto e avaliá-lo. Emitir uma hipótese sobre o comportamento pessoal que seria adotado em função das informaçóes do texto

- Questão 6: Integrar e interpretar: Desenvolver uma interpretação. Identificar o objetivo de um elemento convencional inserido em um texto curto (INEP, 2009).

\footnotetext{
${ }^{6}$ As avaliaçóes do Pisa acontecem a cada três anos e abrangem três áreas do conhecimento - Leitura, Matemática e Ciências havendo, a cada edição do programa, maior ênfase em cada uma dessas áreas. As últimas ediçóes foram: 2009 com o foco sobre o domínio de Leitura; em 2012, matemática; e para 2015, Ciências. O programa é desenvolvido e coordenado pela Organização para Cooperaçáo e Desenvolvimento Econômico (OCDE). Nacionalmente é coordenado pelo Inep - Instituto Nacional de Estudos e Pesquisas Educacionais Anísio Teixeira.

${ }^{7}$ Os objetivos estão disponíveis no texto R401_Supermercado, do PISA (INEP, 2009).
} 
A pontuação consiste em crédito completo, se a resposta corresponde ao objetivo e nenhum crédito, se a resposta não atingir o objetivo ou se estiver em branco. Segue abaixo o texto escolhido e as questôes envolvidas (INEP, 2009):

\begin{tabular}{|l|}
\hline \multicolumn{1}{|c|}{ AVISO COLOCADO NO SUPERMERCADO } \\
\hline Alerta: Alergia a amendoim \\
\hline Biscoitos com recheio de limão \\
\hline Data do alerta: 4 de fevereiro \\
\hline Fabricante: Fine Foods Ltd \\
\hline $\begin{array}{l}\text { Informaçôes sobre o produto: Biscoitos com recheio de limão, } 125 \mathrm{~g} \text { (Data de } \\
\text { validade: } 18 \text { de junho e Data de validade: } 1^{\circ} \text { de julho). }\end{array}$ \\
\hline $\begin{array}{l}\text { Detalhes: Alguns dos biscoitos desses lotes podem conter pedaços de amendoim, } \\
\text { que não aparecem na lista de ingredientes. As pessoas alérgicas a amendoim não } \\
\text { devem comer esses biscoitos. }\end{array}$ \\
\hline $\begin{array}{l}\text { Recomendação aos consumidores: Caso tenha comprado esses biscoitos, você } \\
\text { poderá devolvê-los no local da compra, para ser reembolsado integralmente. Para } \\
\text { mais informaçôes, ligue para } 0800034 \text { 241. }\end{array}$ \\
\hline
\end{tabular}

\section{Questáo 2 - AVISO COLOCADO NO SUPERMERCADO R401Q02}

Qual é o objetivo deste aviso?

A. Fazer propaganda dos biscoitos com recheio de limão.

B. Indicar quando os biscoitos foram fabricados.

C. Alertar sobre os biscoitos.

D. Explicar onde comprar os biscoitos com recheio de limáo.

Questáo 3: AVISO COLOCADO NO SUPERMERCADO R401Q03 - 019

Qual é o nome da empresa que fez os biscoitos?

\section{Questão 4: AVISO COLOCADO NO SUPERMERCADO R401Q04}

Qual é o objetivo da parte intitulada Detalhes?

A. Fazer propaganda de diferentes tipos de biscoito.

B. Descrever uma oferta especial dos biscoitos.

C. Citar os ingredientes dos biscoitos.

D. Explicar o que há de errado com os biscoitos.

Questáo 5: AVISO COLOCADO NO SUPERMERCADO R401Q05 - 019

$\mathrm{O}$ que você faria se tivesse comprado esses biscoitos?

Por que você faria isso?

Use as informações do texto para justificar a sua resposta.

Questão 6: AVISO COLOCADO NO SUPERMERCADO R401Q06 - 019

Por que o alerta menciona as "datas de validade"? 


\section{RESUlTAdos E DiscuSSÃo}

\subsection{O DESEMPENHO DE LÉO}

Léo nasceu surdo, iniciou o contato com a língua de sinais aos 12 meses de idade, sua família é ouvinte e não há outros parentes surdos. Sua trajetória escolar sempre envolveu a língua de sinais com pares surdos e Intérpretes Educacionais. No teste de compreensão de Língua de Sinais teve $100 \%$ de acerto em todas as tarefas de avaliação. No teste de compreensão de leitura da língua portuguesa, todas as questôes tiveram créditos completos. $\mathrm{O}$ resumo do texto feito por ele durou 42 segundos e abrangeu as informaçóes mais importantes do texto, acontecimento, consequência e reação, finalizando com o objetivo da informação presente no texto.

\subsection{O desempenho de CRIS}

Cris teve sua surdez descoberta pelos pais aos três anos de idade. Aos quatro anos frequentou uma instituição que treinava a fala e também sinais e tinha contato com outras crianças surdas, mas poucas vezes. Sua trajetória escolar da $1^{\mathrm{a}}$ até a $6^{\mathrm{a}}$ série do ensino fundamental não envolveu a língua de sinais, fazia leitura labial e alguns gestos. Foi a partir dos 15/16 anos que passou a ter maior contato com a língua de sinais efetivamente. No teste de compreensão de Língua de Sinais teve $100 \%$ de acerto em todas as tarefas de avaliação. No teste de compreensão de leitura da língua portuguesa, Cris não atingiu o objetivo das Questóes 2 (múltipla escolha) e 6 (dissertativa que envolve a explicação sobre um elemento do texto), ou seja, náo conseguiu identificar a ideia principal do texto associando duas informaçóes adjacentes e nem identificar o objetivo de um elemento convencional inserido no texto. Seu resumo durou 51 segundos, bem estruturado em língua de sinais, mas não demostrou compreensão das informações do texto. Não foi citado em nenhum momento sobre a possibilidade dos biscoitos terem em sua formulação traços de amendoim e ainda houve distorção sobre a questão das datas de validade.

\subsection{O DeseMPENHO DE BETO}

Beto nasceu surdo e aos oito anos foi para uma escola de surdos em regime de internato onde aprendeu a língua de sinais com adultos surdos. Em toda sua trajetória escolar a língua de sinais esteve presente. No teste de compreensão de Língua de Sinais teve 100\% de acerto em todas as tarefas de avaliação. No teste de compreensão de leitura da língua portuguesa, Beto não atingiu o objetivo das Questóes 2 e 4 (múltipla escolha) e 6 (dissertativa que envolve a explicação sobre um elemento do texto), ou seja, não conseguiu identificar a ideia principal do texto associando duas informaçôes adjacentes, não identificou o objetivo de uma parte do texto e nem o objetivo de um elemento convencional inserido no texto. Seu resumo durou 56 segundos e igualmente mostrado nas repostas das questôes, a compreensão ficou comprometida. A questão da presença do amendoim não foi anunciada e houve equívoco em relação à informação sobre a data de validade.

\subsection{O desempenho de Pedro}

Pedro nasceu surdo e até os 15 anos comunicava-se por gestos caseiros e leitura labial de familiares. Tem dois irmãos surdos, mais velhos, que não frequentaram a escola. Sua trajetória escolar iniciou com a terapia da fala. Estudou em escola regular, sem outros surdos e 
sem intérprete de Libras. A partir dos 15 anos teve contato com adultos surdos, que lhe ensinaram a língua de sinais e somente no Curso de Graduação teve Intérprete de Libras, em sala de aula. No teste de compreensão de Língua de Sinais teve 100\% de acertos em todas as tarefas de avaliação. No teste de compreensão de leitura da língua portuguesa, Pedro não atingiu o objetivo das Questóes 5 e 6 (dissertativa que envolve a explicação sobre um elemento do texto), ou seja, não conseguiu refletir sobre o conteúdo de do texto e avaliá-lo, emitir uma hipótese sobre o comportamento pessoal que seria adotado em funçáo das informaçóes do texto e nem identificar o objetivo de um elemento convencional inserido no texto. Seu resumo durou dois minutos e 10 segundos e confirmou a não compreensão das informaçóes do texto. Mais uma vez a questão da presença do amendoim não foi anunciada e também houve equívoco em relação à informação sobre a data de validade.

\subsection{O desempenho de Felipe}

Felipe nasceu surdo, recebeu educação oralista e em casa. A mãe dedicou-se a lhe ensinar as primeiras palavras. Seu primeiro contato com a língua de sinais se deu aos 25 anos no término do Curso de Graduação. No teste de compreensão de Língua de Sinais teve 100\% de acerto em todas as tarefas de avaliação. No teste de compreensão de leitura da língua portuguesa, Felipe não atingiu o objetivo das Questóes 4 (múltipla escolha), 5 e 6 (dissertativa que envolve a explicação sobre um elemento do texto), ou seja, não conseguiu identificar o objetivo de uma parte do texto informativo curto, não conseguiu refletir sobre o conteúdo do texto e avaliá-lo. Também não emitiu uma hipótese sobre o comportamento pessoal que seria adotado em função das informaçóes do texto e nem identificou o objetivo de um elemento convencional inserido no texto. Seu resumo durou 1 minuto e 59 segundos. Abordou todas as informaçóes do texto, porém cometeu o mesmo equívoco que os outros participantes sobre a informação das datas de validade. Vale destacar que, no resumo em Libras, Felipe evidenciou a possibilidade dos biscoitos terem amendoim e não constar na lista de ingredientes, o que leva a entender que talvez não tenha compreendido a Questão 5 em Libras, devido à resposta equivocada que escreveu no formulário, considerando também o pouco tempo de aquisição da Libras (um ano e oito meses).

Visão geral dos acertos no Gráfico 1: 


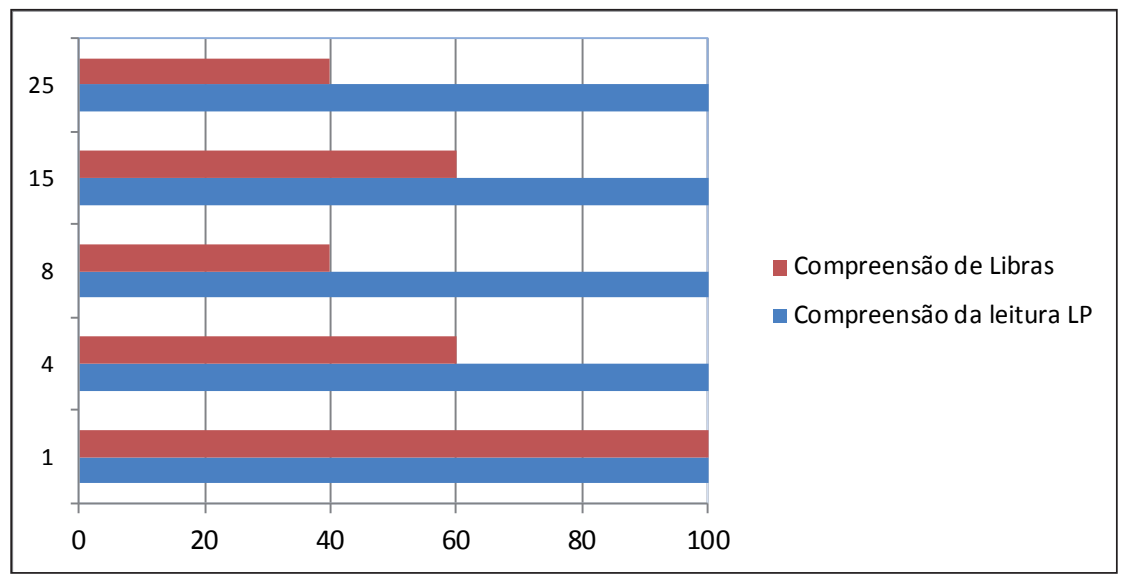

Gráfico 1 - Idade de aquisição da língua de sinais e o percentual de acerto nos testes de compreensão leitora.

Fonte: elaboração própria.

A análise dos dados mostrou primeiramente que os participantes da pesquisa tiveram um bom rendimento na compreensão da língua brasileira de sinais, mesmo que com atraso na idade de aquisição, no entanto o fator idade de aquisição da língua brasileira de sinais por surdos mostrou-se interferir bastante na compreensão leitora da língua portuguesa como segunda língua. Contudo, há outros fatores a considerar como: o contato com outros surdos que sejam fluentes; o apoio e motivação da família no uso das duas línguas (Libras e Língua Portuguesa) tanto aprendendo a língua de sinais para uma comunicação eficiente como criando o hábito da leitura da língua portuguesa; a presença da língua de sinais durante a trajetória escolar; bem como metodologias de ensino de língua portuguesa que auxiliem os surdos a descobrir suas próprias estratégias de construçáo de sentido e ainda os fazerem detectar as diferenças de modalidade das línguas produzidas, as particularidades próprias da língua portuguesa quanto as $\mathrm{da}$ língua de sinais, e ainda, o que é comum a ambas as línguas.

Léo adquiriu da língua brasileira de sinais no período crítico (um ano de idade), teve o apoio da família que optou por aprender a língua de sinais e participar ativamente da comunidade surda envolvendo-se com os movimentos sociais surdos, os quais sấo fatores que contribuíram para o ótimo desempenho em ambos os testes.

Cris e Pedro tiveram o mesmo desempenho, ambos não tiveram escolarização através da língua de sinais até os 15 anos de idade. Pedro utilizava sinais caseiros com seus irmãos surdos mais velhos, os quais não puderam ir à escola e também não se apropriaram da língua de sinais antes da idade adulta.

Beto, apesar de ter presente a língua de sinais em quase toda trajetória escolar e ter se tornado fluente, iniciou com oito anos sua escolarização, o que já evidenciou um atraso na aquisição da linguagem, além de não possuir o estímulo da família. A aquisição da linguagem para Felipe deu-se pela oralização e leitura labial e veio a aprender a Libras já com 25 anos, mas seu desempenho igualou-se ao de Beto. 
Cris, Beto, Pedro e Felipe tiveram em comum a não compreensão da Questão 6 que solicita explicar porque o alerta menciona as datas de validades, todos associaram as datas de validade ao seu significado comum, o prazo adequado para consumo, deixando de relacionar a pergunta ao texto, fato que evidencia as falhas metodológicas no ensino da língua portuguesa para surdos.

É urgente a necessidade de uma reformulação curricular nas escolas que atendem alunos surdos, é preciso incluir o ensino de leitura e escrita da língua portuguesa como segunda língua para os surdos, no turno de aula comum. O ensino da língua portuguesa oferecido hoje pelo Ministério da Educação não condiz com as necessidades dos surdos:

[...] o Atendimento Educacional Especializado para o ensino da Língua Portuguesa acontece na sala de recursos multifuncionais e em horário diferente ao da sala comum. O ensino é desenvolvido por um professor, preferencialmente, formado em Língua Portuguesa e que conheça os pressupostos linguísticos teóricos que norteiam o trabalho, e que, sobretudo acredite nesta proposta estando disposto a realizar as mudanças para o ensino do português aos alunos com surdez (DAMÁZIO, 2007, p.38).

Frente ao exposto por Damázio (2007), indaga-se: o que se aprende nas aulas de língua portuguesa, no horário escolar comum? Há muito que se debater e pôr em prática no campo de ensino de leitura e escrita da língua portuguesa para surdos.

É importante registrar que durante o teste de compreensão de língua de sinais havia certa afetividade, pois todos estavam à vontade. No teste de língua portuguesa, havia certa tensão, preocupação em responder corretamente, com sentimentos de insegurança provenientes das experiências que já tiveram com a língua portuguesa.

Pode-se inferir que o atraso da aquisição da linguagem afeta as habilidades de construção de sentidos do texto e associação entre os conhecimentos prévios e a mensagem do texto, visto que o processo de leitura envolve os conhecimentos prévios armazenados nas várias memórias, que serão utilizados simultaneamente com as informações linguísticas do texto. Os conhecimentos prévios, linguísticos ou extralinguísticos, guiam os olhos do leitor na busca das pistas e encaminham as inferências durante o processo de leitura, considerados esquemas cognitivos, que resultam de representações do mundo e que são internalizadas pelo indivíduo (PEREIRA; SCLIAR-CABRAL, 2012).

As representaçóes de mundo dependem de como se interage com o meio em que se vive. A criança surda necessita da língua como instrumento de interaçáo, língua que deve ser acesso natural e que possibilite a construção e reconstrução de esquemas cognitivos, imprescindíveis à compreensão leitora.

\section{Conclusótes}

Sabe-se que, no contexto brasileiro, a língua de sinais foi legalmente reconhecida há pouco mais de dez anos, mas ainda enfrenta resistência em sua aceitação na sociedade em geral. Por outro lado, ainda não há programas governamentais de informação às famílias, que têm filhos surdos, sobre a importância da língua de sinais nos primeiros anos de vida. Além disso, verifica-se a falta de apoio à escolarização bilíngue, sendo que a língua de sinais é a língua de instrução e de construção do conhecimento. A língua portuguesa é uma segunda língua, em sua 
modalidade escrita, sem ter um consenso sobre um programa de educação de qualidade para os Surdos. Pesquisas sobre bilinguismo, aquisição da linguagem, processos de letramento, compreensão leitora em segunda língua são imprescindíveis na construção de políticas linguísticas, que permitam aos Surdos formarem-se como cidadãos. Espera-se que o presente estudo possa ser repetido por outros pesquisadores, em um número maior de participantes, com possibilidade de comparação entre gêneros e situação econômica ampliando o debate sobre a complexa área da compreensão leitora da língua portuguesa como segunda língua para surdos.

\section{REFERÊNCIAS}

DAMÁZIO, M.F.M. Atendimento educacional especializado: pessoa com surdez. SEESP/SEED/MEC. Brasília, DF, 2007. Disponível em: <http://portal.mec.gov.br/seesp/arquivos/pdf/aee_da.pdf>. Acesso em: 22 jan. 2014.

FERNANDES, S.; MOREIRA, L.C. Desdobramentos político-pedagógicos do bilinguismo para surdos: reflexóes e encaminhamentos. Revista Educação Especial, Santa Maria, v.22, n.34, p.225-236, 2009. Disponível em: <http://cascavel.ufsm.br/revistas/ojs-2.2.2/index.php/educacaoespecial/article/ view/275>. Acesso em: 07 out. 2013.

FERRARI, M. A hipótese do periodo crítico no aprendizado da lingua estrangeira analisada à luz do paradigma conexionista. 2007. 232f. Tese (Doutorado em Linguística) - Faculdade de Letras, Universidade Católica do Rio Grande do Sul, Porto Alegre, 2007.

INEP. Letramento em Leitura. 2010. In: Marcos Referenciais. Disponível em: <http://download.inep. gov.br/download/internacional/pisa/2010/letramento_leitura.pdf>. Acesso em: 21 out. 2013.

INEP. Itens: PISA. 2009. Disponível em: <http://portal.inep.gov.br/internacional-novo-pisa-itens>. Acesso em: 21 out. 2013.

KOCH, I.V.; ELIAS, V.M. Ler e compreender: os sentidos do texto. 2. ed. São Paulo: Contexto, 2006.

LENNEBERG, E.H. Biological foundations of language. New York: John Wiley, 1967.

LÜDKE, M; ANDRÉ, M.E. Pesquisa em educaçâo: abordagens qualitativas. São Paulo: EPU, 1986.

MARTINS, S.E.S.O. Formação de leitores surdos e a educação inclusiva. 2005. 277f. Tese (Doutorado em Educação) - Faculdade de Filosofia e Ciências, Universidade Estadual Paulista, Marília, 2005.

MAYBERRY, R. I.; LOCK, E. Age constraints on first versus second language acquisition: Evidence for linguistic plasticity and epigenesis. Brain and Language, v.87, p.369-383, 2003. Disponível em: <http://grammar.ucsd.edu/mayberrylab/papers/Mayberry\&Lock03.pdf>. Acesso em: 21 out. 2013.

PEREIRA, V.W.; SCLIAR-CABRAL, L. Compreensão de textos e consciência textual: caminhos para o ensino nos anos iniciais. Florianópolis: Insular, 2012.

PETITTO, L.A.; MARINETTE, P.A. Babbling in the manual mode: evidence for the ontogeny of language. Reprinted from: Science, v.251, p.1483-1496, 1991.

QUADROS, R.M. Educação de surdos: a aquisição da linguagem. Porto Alegre: Artmed, 1997.

QUADROS, R.M. O paradigma gerativista e a aquisição da linguagem. In: FINGER, I; QUADROS, R.M. (Org.). Teorias de aquisição da linguagem. 1.ed. Petrópolis: Editora da UFSC, 2008.

QUADROS, R.M; KARNOPP, L.B. Lingua de sinais brasileira: estudos linguísticos. Porto Alegre: Artmed, 2004. 
QUADROS, R.M; CRUZ, C.R. Lingua de sinais: instrumentos de avaliação. Porto Alegre: Artmed, 2011. RAMÍREZ, N.F.; LIEBERMAN, A.M.; MAYBERRY, R.I. The initial stages of first language acquisition begun in adolescence: when late looks early. Journal of Child Language, Bethesda, v.40, p.391-414, 2012.

RUIZ, J.R.G.; ORTEGA, J. L. G. As perturbaçôes da linguagem verbal. In: BAUTISTA, R. (Org.). Necessidades educativas especiais. Lisboa: Dinalivro, 1993. p.83-108.

STROBEL, K. As imagens do outro sobre a cultura surda. Florianópolis: Ed. da UFSC, 2008.

VENTURA, M. M. O estudo de caso como modalidade de pesquisa. Pedagogia Médica, Revista SOCERJ, v.20, p.383-386, 2007. Disponível em: <http://sociedades.cardiol.br/socerj/ revista/2007_05/a2007_v20_n05_art10.pdf>. Acesso em 21 out. 2013.

Recebido em: 12/08/2014

Reformulado em: 18/05/2015

Aprovado em: 23/06/2015 